\title{
Effect of near adds on the variability of accommodative response in myopic children
}

Vidhyapriya Sreenivasan, BSOptom, MSc; Elizabeth L Irving, OD, PhD; William R Bobier, OD, $\mathrm{PhD}, \mathrm{FAAO}$

School of Optometry, University of Waterloo, Ontario, Canada

Running title: Near adds and variability of accommodation in myopes

Number of tables: one

Number of figures - 4

Corresponding author:

Vidhyapriya Sreenivasan

School of Optometry

200, University Avenue West

Waterloo, Ontario

Canada-N2L 3G1

Email address: vsreeniv@sciborg.uwaterloo.ca

Phone number: (519) 7298100 


\section{$\underline{\text { Abstract }}$}

Purpose: Higher variability of accommodative response (VAR) has been reported in myopes and speculated to be a possible risk factor for the progression of myopia. We investigated whether near (+2D and -2D) adds are capable of altering accommodative variability and also determine the influence of near phoria and viewing condition (binocular vs. monocular) on the VAR in myopic and emmetropic children.

Methods: 27 myopic and 25 emmetropic children between 7 and 14 years were examined. All children were classified into "normophores" (0 to 4 exo), exophores (>6 exo) or esophores ( $>2$ eso) based on their near phoria. Binocular and monocular steady-state measures of accommodation were obtained for 5 sec using a PowerRefractor (Multichannel Co) while children fixated a high contrast target $(33 \mathrm{~cm})$ with distance correction, and then with $+2 \mathrm{D}$ add and -2D add over the corrective lenses. The variation in accommodative responses (VAR) was defined as the standard deviation of the accommodative response during the 5 sec period.

Results: Myopic children showed higher VAR through their distance spectacle corrections compared to emmetropes $(E m m=0.23 \pm 0.03 \mathrm{D} ; \mathrm{Myo}=0.37 \pm 0.07 \mathrm{D} ; \mathrm{P}<0.001)$. Plus adds significantly reduced the VAR in myopic children to the level of emmetropes (Emm $=0.2 \pm 0.03 \mathrm{D}$; $\mathrm{Myo}=0.19 \pm 0.02 \mathrm{D} ; \mathrm{P}>0.9$ ). Introduction of a $-2 \mathrm{D}$ add significantly increased the VAR in both refractive groups; however, myopes showed greater VAR compared to emmetropes (Emm $=0.39 \pm$ 0.03D; $\mathrm{Myo}=0.53 \pm 0.07 \mathrm{D} ; \mathrm{P}<0.001$ ). Near phoria or binocular viewing did not alter the magnitude of fluctuations in either refractive group. VAR significantly correlated with the monocular accommodative error in both refractive groups $\left(E m m r^{2}=0.34 ; p<0.0001 ;\right.$ Myo: $\left.r^{2}=0.35 ; p<0.001\right)$. Pupil size while varying with add type, did not confound the VAR. 
Conclusion: The near steady state accommodative response of young myopes shows greater variability than non-myopes. This difference is maintained when accommodative responses are increased beyond the vergence plane using - 2D adds. However, accommodative fluctuations were reduced to emmetropic levels when the stimulus to accommodation is reduced using a +2D add. The resulting VAR through adds appear to follow that expected from variations in accommodative demands and hence properties of the accommodative controller. Vergence postures (eso and exo phoria) do not appear to influence the VAR with and without near adds.

Keywords: Myopia, Accommodative response, Near adds, accommodative microfluctuations 


\section{Introduction}

When focusing a stationary target the accommodative response exhibits small variations in refractive power (around 0.1D-0.5D) termed microfluctuations ${ }^{1-5}$ (see ${ }^{6}$ for review). This variation has been expressed as the root mean square value (RMS) ${ }^{7-10}$ or the standard deviation (SD) of the accommodative response ${ }^{11,12}$ in the time domain and as the amplitude of low, middle and high frequency components in the frequency domain. ${ }^{2,3,7,10,11,13,14}$ Power spectrum analysis of the fluctuation waveform reveals two dominant frequency bands: a wider low frequency component (LFC at $<0.5 \mathrm{~Hz}$ ) and a narrower high frequency component (HFC between 1.3-2.2 Hz) ${ }^{3,6}$ The HFC is believed to result from noise in the accommodative plant and correlates with the systemic arterial pulse. ${ }^{6,13,15}$ The LFC, on the other hand, appears to be an integral part of the accommodative controller system and varies with factors that modulate the depth of focus of the eye. ${ }^{6}$ Small pupil size, ${ }^{7}$ low target luminance ${ }^{8}$ and low spatial frequency content of the target ${ }^{16-18}$ increase the ocular depth of focus, resulting in an increased magnitude of microfluctuations. Several studies also report a significant association between the microfluctuations and stimulus to accommodation such that the magnitude of fluctuations increases with an increase in accommodation. ${ }^{4,5,19}$ The majority of these studies were performed under monocular viewing conditions (i.e. absence of disparity cues to accommodation). However, earlier reports do not report any substantial improvement in the stability of accommodative response under binocular viewing conditions. ${ }^{20,21}$

Recently, numerous studies have reported refractive group differences in the magnitude and power of accommodative fluctuations. Most of these studies show increased microfluctuations in myopes 9,11,12,22 ; however, a few other studies found no relationship between myopia and the variability of accommodative response. ${ }^{14,23}$ This discrepancy may reflect differences in the 
experimental protocols used to measure accommodation, the age of participants and the pattern of their myopic progression. Increased fluctuations have been reported in late-onset myopes, ${ }^{9,22}$ adult early-onset myopes tested during progression, ${ }^{22}$ in stable myopic adults ${ }^{11}$ and in myopic children (progression not defined). ${ }^{12}$ This larger variability has been reported when accommodation was tested under monocular ${ }^{9,22}$ or binocular viewing conditions. ${ }^{11,12}$ Studies show that myopic individuals demonstrate the greatest variability and largest refractive group differences at the closest testing distance. ${ }^{11,12}$ Since myopic children perform near work at closer reading distances, ${ }^{24-26}$ they might constantly experience larger accommodative demands and greater variability of accommodation compared to emmetropes. This may result in hyperopic retinal defocus, which might trigger axial elongation and myopia. ${ }^{27-29}$

Plus adds have been considered as a possible optical treatment in an effort to reduce the progression of myopia. These lenses have been prescribed to reduce accommodation, with the recent rationale of eliminating the large accommodative lags that might trigger axial elongation. ${ }^{30,31}$ Studies that measured accommodative lag through the plus adds show that these lenses are capable of reducing the accommodative lags in myopic adults ${ }^{32}$ and children. ${ }^{33-35}$ Yet, clinical trials indicate that plus adds have been more successful in slowing myopic progression only in some groups such as children with esophoria, ${ }^{36-38}$ combined with larger lags of accommodation. ${ }^{30,}$, 31,37

Phoria, particularly esophoria has been found to be associated with larger accommodative lags, ${ }^{39}$ greater myopia progression, ${ }^{40}$ higher amounts of myopia ${ }^{41}$ and better prognosis of reduction of myopia with near adds. ${ }^{26,31,37}$ It is not clear if increased VAR is found in myopic esophores compared to other phoria groups. Further, it is not known whether near adds have a differential effect on phoria groups. While it would be expected that plus adds would reduce the stimulus to accommodation, it is not clear if like accommodative lag, the plus adds would reduce the variability 
observed in myopic children. On the contrary, since minus lenses increase the demand for accommodation and result in greater lags of accommodation, (more so in myopes compared to emmetropes) ${ }^{42-44}$ they may exaggerate the variability of accommodative response to a greater extent in myopic children. Though several studies have investigated the effect of plus adds on the accommodative response of myopes, ${ }^{33-35}$ to date, no study has measured the influence of plus and minus adds on the variability of accommodative response (VAR) in myopic children. Thus, the aim of this paper is to determine the effect of near adds on the VAR under both binocular and monocular viewing conditions in myopic and emmetropic children with varying degrees and directions of near phorias. Accommodative responses were analysed in the time domain and VAR was expressed as the standard deviation of accommodative response. 


\section{Methods}

This study is a part of a larger study that measured ocular alignment and accommodation in children. Measures of accommodation only are presented in this study.

\section{Study participants}

Fifty three children (28 myopic and 25 emmetropic; 58\% female) between the ages of 7 and 14 years were recruited from the clinic database at the School of Optometry, University of Waterloo. Informed consent (parents) and assent (children) were obtained after verbal and written explanation of the nature of the study. The protocol followed the tenets of Declaration of Helsinki and received approval from the University of Waterloo ethics review board.

Participants with normal general and ocular health (determined from their clinical records and confirmed during a screening visit) underwent preliminary examination to ensure the following: myopic refractive error between -0.75 and $-6 \mathrm{D}$ or emmetropic refractive error between +0.25 and +1.5 D determined using cycloplegic refraction (two drops of $1 \%$ tropicamide added to both eyes, similar to a previous study ${ }^{45}$ ); astigmatism $<1 \mathrm{D}$; anisometropia $<1 \mathrm{D}$; best corrected visual acuity of at least 6/6 in each eye; non-strabismic; normal amplitudes of accommodation; and that participants were not taking any medications that might influence the accommodation and vergence systems. All participants were further divided into “normophores" (0-4 exo), exophores (>6 exo) or esophores ( $>2$ eso) based on their near phoria measured using the modified Thorington technique (MTT) ${ }^{46}$ at $33 \mathrm{~cm}$. Table 1 lists the age and critical visual parameters of the study groups. 


\section{Instrumentation and experimental procedure}

Accommodative responses were obtained using the monocular mode of an eccentric infrared (IR) photorefractor, the PowerRefractor (Multichannel Co, Reutlingen, Germany). ${ }^{47}$ This setting of the instrument determined refraction along the vertical meridian of the participants' eye, sampling at a rate of $25 \mathrm{~Hz}$, coupled with measures of gaze deviations and pupillary diameter. The responses obtained from the PowerRefractor were calibrated using a two-step protocol to ensure relative and absolute accuracy of accommodation similar to previous studies. ${ }^{48-50}$ While the slope of calibration function matched with the instruments default for some participants, others needed separate calibrations functions, possibly due to differences in fundal reflectance. ${ }^{51,52}$ In all cases, accommodative responses were calibrated based on individual calibration equations.

A high contrast colour cartoon (contrast $=85 \%$; target luminance $=15 \mathrm{~cd} / \mathrm{m}^{2}$ ) was used to measure accommodation in children. This target was chosen as it was expected to be more successful than conventional reading material in holding the participants' attention and has been verified to be an effective stimulus for accommodation. ${ }^{49}$ The image of the cartoon was displayed on a 1.77" wide liquid crystal display monitor (Model No: LT-V18 U; Victor company of Japan) and projected at a distance of 33cms through a semi-silvered mirror. The mirror set $10 \mathrm{~cm}$ from the right eye and angled at 45 degrees allowed the photorefractor to simultaneously record accommodation from the right eye during target viewing. The method has been described elsewhere in detail. ${ }^{49}$

The study design consisted of three experimental sessions that were performed on separate days with the order of sessions randomized to avoid bias; one session was performed with the children wearing their corrective lenses (referred to as "no add condition") and the other two 
involved measurements with $+2 \mathrm{D} /-2 \mathrm{D}$ lenses (referred to as "plus and minus add condition") added over their correction (if applicable). A trial frame set $12 \mathrm{~mm}$ from the eye housed ophthalmic lenses, which provided the distance correction and near add. The frame was adjusted for the participants’ near pupillary distances to reduce any prismatic effect.

Prior to the start of each study session, participants were dark adapted for 3 minutes to avoid effects of previous near work. ${ }^{53}$ The lighting in the examination room was then reduced to obtain sufficiently large pupil sizes (greater than $4 \mathrm{~mm}$ as recommended by the manufacturer of PowerRefractor) for the measurement of accommodation. Binocular and monocular measures of accommodation were recorded continuously for a period of 5 sec after confirming steady fixation using the gaze control function displayed on the PowerRefractor interface. For the binocular response, accommodation was recorded from the right eye alone, although both eyes fixated at the target. For measurement of monocular accommodation, the left eye was occluded. During the $5 \mathrm{sec}$ measurement period, the accuracy of fixation was assessed using the gaze control function displayed on the PowerRefractor interface. Additionally, care was taken to ensure that the child was fixating the near target at the correct fixation distance $(33 \mathrm{~cm})$ while measurements were recorded. A volunteer constantly monitored the head position of the child and ensured they did not move away from the chin rest during measurement. If any unsteady fixation was noticed during measurement, or when the examiner (VS) observed off axis gaze errors exceeding 10 degrees, the measures were flagged using keyboard inputs and discarded given the possibility of under or over estimation of accommodation. ${ }^{54,55}$ In these cases, recordings were obtained for an additional $5 \mathrm{sec}$ period to ensure equal data sets across subjects. 


\section{Data Analysis}

VAR was defined as the standard deviation of the accommodative response across the 5 sec period. Each data point was screened and accepted if the following criteria were met: the pupil size was above 4mm; the ocular alignment was less than 10 degrees and 5 degrees from the optical axis of the photorefractor in the horizontal and vertical axes respectively (as recommended by the manufacturer ${ }^{47}$ ) and the responses were free of blinks. Blink artefacts, if any were removed using a method similar to previous studies. ${ }^{49,56}$ Each participant needed to have at least 100 rows of acceptable data after satisfying all of the above criteria in order to be considered for averaging and further analysis. If the participants had more than 100 eligible data points, only the first 100 points were taken for further analysis. The data retained were averaged to obtain the VAR. Data from one myopic participant was excluded from the averaging process since she failed to provide the minimum levels of acceptable data as a result of pupil diameters less than $4 \mathrm{~mm}$.

Mixed-design analysis of variance (ANOVA) was used to determine the effect of $+2 \mathrm{D} /-2 \mathrm{D}$ add condition, phorias, viewing condition, and refractive group on VAR. In all cases, statistically significant main effects were further examined using Tukey Honestly significant differences (HSD) post-hoc tests to determine the group that showed the significant difference. Differences were considered statistically significant when the likelihood of type-I error was $<0.05$. Data analysis was performed using STATISTICA 6.0 (StatSoft, Inc, USA). Pearson correlations were conducted to look for relationships between variables like pupil size, accommodative error and VAR. Analysis of co-variance (ANCOVA) was performed to ensure that pupil size did not confound the main findings. 


\section{$\underline{\text { Results }}$}

\section{VAR through best corrective lenses (no add condition)}

Fig. 1 B (middle) shows representative raw data from a myopic and emmetropic child when fixating a high contrast near target over $5 \mathrm{sec}$ in the no add condition. Visual inspection shows that the myopic child exhibits greater fluctuations in the accommodative response compared to the emmetrope. This pattern (i.e. larger fluctuations in myopes compared to emmetropes- F $(1,94)$ =32.15; $\mathrm{p}<0.001$ ) was found when the mean values were compared in binocular (Fig. $2 \mathrm{~A}$ ) and monocular viewing condition (Fig 2B) in all three phoria groups. The findings were independent of the direction of near phoria $\left(\mathrm{F}_{(2,94)}=0.054 ; \mathrm{p}=0.94\right)$ or viewing condition $\left(\mathrm{F}_{(1,94)}=0.47 ; \mathrm{p}=0.49\right)$.

$<$ INSERT FIGURE 1 HERE $>$

$<$ INSERT FIGURE 2 (A and B) HERE $>$

\section{Variability of accommodative response through $+2 D /-2 D$ near adds}

Fig $1 \mathrm{~A}$ and $\mathrm{C}$ (top and bottom graphs) shows that near adds differentially alters the pattern of VAR in the myopic and the emmetropic child. The plus add reduces the VAR in the myopic child while the normal VAR of the emmetropic child is unchanged. The minus add however, increases the VAR for both the myopic and emmetropic child, but the myopic child shows greater variability than the emmetrope. The mean VAR through plus and minus adds follows the same pattern as the representative raw data. Figs 2A and B shows the VAR in children with different near phorias under binocular and monocular viewing conditions respectively. Statistical analysis showed a significant main effect of add type $\left(\mathrm{F}_{(1,94)}=256.9 .1 ; \mathrm{p}<0.0001\right)$, refractive error $\left(\mathrm{F}_{(1,94)}=9.7 ; \mathrm{p}=0.002\right)$ and a presence of refractive group* add interaction $\left(\mathrm{F}_{(1,94)}=17.12\right.$; $\left.\mathrm{p}<0.0001\right)$ but no main effect of phoria 
$\left(F_{(2,94)}=0.31 ; p=0.73\right)$ and no main effect of viewing condition (binocular vs. monocular) $\left(\mathrm{F}_{(1,94)}\right.$ $=1.7 ; \mathrm{p}=0.18)$. Post-hoc results revealed that plus adds significantly reduced $(\mathrm{P}<0.05)$ the VAR in all phoria groups of myopic children to a level equal to that of emmetropes (Grouped mean: $\mathrm{Emm}=0.2 \pm 0.03 \mathrm{D} ; \mathrm{Myo}=0.19 \pm 0.02 \mathrm{D} ; \mathrm{P}>0.9)$. However, emmetropic controls did not show any significant change in VAR through the plus adds. On the other hand, minus adds significantly increased $(\mathrm{P}<0.001)$ the VAR in both emmetropes and myopes compared to the $+2 \mathrm{D}$ and the no add conditions but myopic groups exhibited significantly higher VAR $(\mathrm{P}<0.001)$ compared to emmetropic children (Grouped mean: Emm=0.4 \pm 0.03D; $\mathrm{Myo}=0.53 \pm 0.07 \mathrm{D} ; \mathrm{P}=0.01$ ). For both add types, near phoria or binocular vs. monocular viewing did not alter the pattern of VAR in either refractive groups.

\section{Effect of pupil size on the VAR}

Evidence has shown that VAR increases as pupil size decreases. ${ }^{3,7}$ Hence it is important to investigate whether changes in pupil size contributed to the differences in VAR observed between the add conditions and the refractive groups. For the purpose of this analysis, data from all phoria groups were combined together as near phoria did not influence the VAR in any of the add conditions. ANOVA showed a significant main effect of add type $\left(\mathrm{F}_{(1,49)}=57.9 ; \mathrm{p}<0.001\right)$ but not refractive group $\left(\mathrm{F}_{(1,49)}=1.6 ; \mathrm{p}=0.22\right)$ and no significant interaction between add type and refractive group $\left(\mathrm{F}_{(1,49)}=0.17 ; \mathrm{p}=0.67\right)$. Post-hoc comparisons show that the mean pupil size was significantly $(\mathrm{P}=0.005)$ decreased through the minus add $(\mathrm{Emm}=5.2 \pm 0.2 \mathrm{D} ; \mathrm{Myo}=4.9 \pm 0.07 \mathrm{D})$ compared to the plus add $(E m m=5.8 \pm 0.2 \mathrm{D} ; \mathrm{Myo}=5.6 \pm 0.15 \mathrm{D})$ as expected in both refractive groups. However, the diameter of the pupil did not significantly differ between refractive groups in any of the add conditions. Furthermore, to ensure that decreased pupil size was not the only cause for increased variability observed through the minus add, an analysis of co-variance was performed 
with pupil diameter as a co-variate. ANCOVA confirmed a significant effect of add type and refractive error on the VAR with a constant pupil size.

\title{
Effect of accommodative error on the VAR
}

Fig 3 shows the mean monocular accommodative response in the two refractive groups (with phoria groups collapsed) through the three test conditions. Myopic children show significantly less accommodative response compared to emmetropes in the no add $(\mathrm{Myo}=2.08 \pm 0.12 \mathrm{D}$; $\mathrm{Emm}=2.34 \pm 0.07 \mathrm{D} ; \mathrm{P}=0.02)$ and minus add conditions $(\mathrm{Myo}=3.27 \pm 0.15 \mathrm{D} ; \mathrm{Emm}=3.63 \pm 0.09 \mathrm{D}$; $\mathrm{P}=0.01)$ but not when viewing through plus addition lenses $(\mathrm{Myo}=0.98 \pm 0.11 \mathrm{D} ; \mathrm{Emm}=1.12 \pm 0.1 \mathrm{D}$; $\mathrm{P}=0.3$ ). Moreover, accommodative error (calculated as the difference between accommodative stimulus and accommodative response where positive number denotes lag and negative number denotes lead of accommodation) correlated significantly with the VAR such that larger accommodative errors were associated with greater variability of accommodative response in both refractive groups (Fig 4, MYO: $\mathrm{r}^{2}=0.34 ; \mathrm{p}<0.001$; $\mathrm{EMM} \mathrm{r}^{2}=0.35 ; \mathrm{p}<0.0001$ ). Linear regression analysis of accommodative error and VAR (Fig 4) shows similar slopes (Myo=0.09 $\pm 0.01 \mathrm{D}$; Emm $=0.06 \pm 0.01 \mathrm{D}$ ) significantly different intercepts between the refractive groups $(\mathrm{Myo}=0.30 \pm 0.02 \mathrm{D} ; \mathrm{Emm}=0.24 \pm 0.01 \mathrm{D})$. This suggests that both refractive groups show similar rate of increase/decrease in VAR with increase/decrease in lag respectively but myopes show greater VAR than emmetropes.

\author{
$<$ INSERT FIGURE 3 HERE> \\ $<$ INSERT FIGURE 4 HERE>
}




\section{$\underline{\text { Discussion }}$}

The primary finding of this study is that plus and minus adds have a differential effect on the VAR in myopic and emmetropic children. Plus adds reduced the VAR for myopic but not for emmetropic children such that myopes exhibit fluctuations that are reduced to a level equal to emmetropes. Minus adds, on the other hand, increased the VAR in both refractive groups; however, the increased variation found in myopic children through best corrective lenses were maintained with the negative add. Vergence posture (eso or exo) did not alter the pattern of VAR to plus/minus adds in either myopic or emmetropic group. Further, the fluctuations through near adds were not significantly modified whether accommodation was driven monocularly or binocularly. The VAR significantly correlated with the accommodative error in both refractive groups, suggesting that the change in accommodative demand induced by the adds would explain their effect on the VAR.

It is well known that near adds alter the accommodative demand depending on the magnitude and direction of the add. In this study, the accommodative target was placed at $33 \mathrm{~cm}$ (accommodative demand=3D), thus fixation through $+2 \mathrm{D}$ and $-2 \mathrm{D}$ adds changed the accommodative demand to $1 \mathrm{D}$ and 5D respectively. Past studies show that the accommodative response becomes more variable with an increase in accommodative demand. ${ }^{4,5,9,11,12,19}$ This finding is partly supported in our emmetropic sample since the VAR increased when the accommodative response increased through a minus add (mean increase $=0.17 \pm 0.03 \mathrm{D}$ ) but did not show a significant reduction when accommodation was relaxed through a $+2 \mathrm{D}$ add (mean decrease $=0.04 \pm 0.03 \mathrm{D}$ ). This may be because emmetropes exhibited small fluctuations to a 3D stimulus $($ Mean $=0.23 \pm 0.07 \mathrm{D})$ and it is possible that there is a floor effect such that VAR cannot decrease considerably beyond a certain extent due to the mechanical and elastic properties of the accommodative plant. ${ }^{5,6}$ Further, these results are similar to a previous study, which also showed 
no significant change in the stability of accommodation for similar stimuli (1.25 and 3D) in emmetropic adults. ${ }^{10}$ Myopic individuals showed the expected ${ }^{4,5,9,11,12,19}$ decrease and increase in VAR when accommodative demand was changed to $1 \mathrm{D}$ and 5D through the plus and minus adds respectively. Refractive group differences in VAR were only observed for the higher accommodative demands (3D and 5D) consistent with previous studies. ${ }^{11,12}$

An important outcome of this study is the presence of a significant association between accommodative error and VAR in both refractive groups (Fig 4). It is known that accommodative error varies with the stimulus to accommodation such that greater accommodative lags are seen through minus lenses ${ }^{42-44}$ and reduced accommodative lags are observed through plus adds. $32,34,35,49,57,58$ While our results agree with these findings in both myopes and emmetropes, it is also interesting to note that the refractive group differences in the accommodative response closely match the pattern of VAR seen in the three add conditions. Myopic children show larger accommodative lags compared to emmetropes in the no add and minus add conditions but not through the plus add. However, past studies do not show refractive differences in the accommodative response (through corrective lenses) or a correlation between accommodative error and VAR under binocular viewing conditions. ${ }^{11,12}$ Harb et al ${ }^{11}$ showed a linear relationship between the accommodative response and VAR and also reported that lags increased with closer reading distance in stable adult myopes. But, it is not clear whether past studies find any association between accommodative error and variability. The increased VAR in myopes has been attributed to reduced blur sensitivity. ${ }^{9,11,12}$ Adult myopes are less sensitive to defocus signals that drive accommodation compared to emmetropes, ${ }^{59}$ although a similar study in children suggest myopes may have similar blur detection thresholds compared to age matched emmetropes. ${ }^{60}$ If myopes have elevated blur thresholds, then the accommodative response of a myopic eye could also be 
reduced since these individuals may not perceive the blur that is required to drive any changes in the accommodative system. However, in some of the past studies, increased VAR was found in myopes who did not show greater lags compared to emmetropes even at higher stimulus levels. ${ }^{11,12}$ Larger lags have been reported when myopia is progressing but the response improves as the refractive error stabilizes. ${ }^{43,44}$ Though this study did not measure progression prospectively, review of past clinical records indicate that 18 out of 27 myopes progressed by at least $0.25-0.50 \mathrm{D} / \mathrm{yr}$. Six participants did not have more than one exam at the School of Optometry to determine the amount of progression and 3 had stable refraction. The larger accommodative lags may be due to the progressive nature of the refractive error in this study population. Nevertheless, past evidence indicates that the increase in hyperopic defocus/ more blurred target associated with larger accommodative errors may contribute to the change in accommodative microfluctuation ${ }^{17}$.

The differential effect of plus and minus adds on the two refractive groups may be attributed to factors such as small pupil diameter ${ }^{3,7,19,61}$ or low target luminance ${ }^{8,61}$ that alter the depth of focus thereby increasing the microfluctuations. However, these factors were either controlled or did not change between the refractive groups and therefore are not likely responsible for the observed pattern of VAR through near adds. In this study, pupil diameter did show small and significant reductions when accommodation was increased through -2D add. Yet, this decrease cannot completely explain the higher VAR seen through minus adds since analysis of covariance showed a significant effect of the add despite holding pupil size constant. Moreover, it is unlikely that this reduction can explain the changes in VAR between the add conditions since pupil diameter was always greater than $4 \mathrm{~mm}$ (as recommended by the manufacturer) for both the add conditions in all children. Previous work suggests that depth of focus is not significantly increased until pupil diameter becomes $<2 \mathrm{~mm}$ or $<3 \mathrm{~mm}$. ${ }^{3,7,61}$ In addition, there were no refractive group differences in 
the pupil diameter in any of the add conditions, similar to previous studies ${ }^{62}$, suggesting that pupil size did not influence the refractive differences observed in the current study. Other factors such as low target luminance also cannot explain the results because the target luminance was much higher $\left(15 \mathrm{~cd} / \mathrm{m}^{2}\right)$ than the levels that increase the depth of focus $\left(0.004-0.002 \mathrm{~cd} / \mathrm{m}^{2}\right)^{8}$ and kept constant between add conditions and refractive groups.

Esophoria is associated with higher amounts ${ }^{41}$ or progression of myopia. ${ }^{40}$ In the present study, myopic esophores did not show larger VAR compared to exophores or phoria normals. These findings could be attributed to the similarity in refractive error between the phoria groups (Table 1). On the other hand, it could be argued that the similarity in refractive error provides a means to conclusively show that the direction of phoria does not influence the stability of accommodative response in a myopic eye. Clinical trials that measured the efficacy of near adds show that only some groups such as esophores ${ }^{36-38}$ or esophores combined with higher accommodative lags show a meaningful reduction in progression of myopia. ${ }^{26,31}$ It would appear that VAR is not a critical factor in this effect as the present study shows that myopes in all phoria groups show a reduction in VAR through plus adds. Further longitudinal studies in progressive myopic children may be helpful in determining the role of VAR and plus adds in the development and progression of myopia. 


\section{$\underline{\text { Acknowledgements }}$}

The authors acknowledge the following people for their assistance: Robin Jones and Andrew Nowinski for technical support; Volunteers Tonia To and Sinthujah Jeyerasalingam for help in monitoring the children's attention during measurements. This study was supported by grants from Canada Foundation for Innovation; NSERC Canada (WRB, ELI); CRC (ELI), COETF (VS,WRB,ELI); AOF Ezell fellowship sponsored by Bausch \& Lomb (VS).

A part of this work was presented as a poster at the 2009 Annual meeting of the Association for Research in Vision and Ophthalmology, Fort Lauderdale. 


\section{$\underline{\text { References }}$}

(1) Alpern M. Variability of accommodation during steady fixation at various levels of illuminance. J.Opt.Soc.Am. 1958; 48:193-197.

(2) Campbell Fw, Westheimer G, Robson Jg. Significance of fluctuations of accommodation. J.Opt.Soc.Am. 1958; 48:669.

(3) Campbell Fw, Robson Jg, Westheimer G. Fluctuations of accommodation under steady viewing conditions. J.Physiol. 1959; 145:579-594.

(4) Denieul P. Effects of stimulus vergence on mean accommodation response, microfluctuations of accommodation and optical quality of the human eye. Vision Res. 1982; 22:561-569.

(5) Kotulak JC, Schor CM. Temporal variations in accommodation during steady-state conditions. J.Opt.Soc.Am.A 1986; 3:223-227.

(6) Charman WN, Heron G. Fluctuations in accommodation: a review. Ophthalmic Physiol.Opt. 1988;8:153-164.

(7) Gray LS, Winn B, Gilmartin B. Accommodative microfluctuations and pupil diameter. Vision Res 1993; 33:2083-2090.

(8) Gray LS, Winn B, Gilmartin B. Effect of target luminance on microfluctuations of accommodation. Ophthalmic Physiol.Opt 1993; 13: 258-265.

(9) Day M, Strang NC, Seidel D, Gray LS, Mallen EA. Refractive group differences in accommodation microfluctuations with changing accommodation stimulus. Ophthalmic Physiol.Opt. 2006; 26:88-96.

(10) Candy TR, Bharadwaj SR. The stability of steady state accommodation in human infants. J.Vis. 2007; 7 :1-16.

(11) Harb E, Thorn F, Troilo D. Characteristics of accommodative behavior during sustained reading in emmetropes and myopes. Vision Res. 2006; 46: 2581-2592.

(12) Langaas T, Riddell PM, Svarverud E, Ystenaes AE, Langeggen I, Bruenech JR. Variability of the accommodation response in early onset myopia. Optom.Vis.Sci. 2008; 85 :37-48.

(13) Winn B, Charman WN, Pugh JR, Heron G, Eadie AS. Perceptual detectability of ocular accommodation microfluctuations. J.Opt.Soc.Am.A 1989; 6:459-462.

(14) Schultz KE, Sinnott LT, Mutti DO, Bailey MD. Accommodative fluctuations, lens tension, and ciliary body thickness in children. Optom.Vis.Sci. 2009; 86: 677-684. 
(15) Collins M, Davis B, Wood J. Microfluctuations of steady-state accommodation and the cardiopulmonary system. Vision Res. 1995; 35: 2491-2502.

(16) Bour LJ. The influence of the spatial distribution of a target on the dynamic response and fluctuations of the accommodation of the human eye. Vision Res. 1981; 21: 1287-1296.

(17) Niwa K, Tokoro T. Influence of spatial distribution with blur on fluctuations in accommodation. Optom.Vis.Sci. 1998;75: 227-232.

(18) Day M, Gray LS, Seidel D, Strang NC. The relationship between object spatial profile and accommodation microfluctuations in emmetropes and myopes. J.Vis. 2009 ;9 : 1-13.

(19) Stark LR, Atchison DA. Pupil size, mean accommodation response and the fluctuations of accommodation. Ophthalmic Physiol.Opt. 1997;17: 316-323.

(20) Campbell FW. Correlation of accommodation between the two eyes. J.Opt.Soc.Am. 1960;50:738.

(21) CAMPBELL FW. The accommodation response of the human eye. Br.J.Physiol.Opt. 1959;16:188-203.

(22) Seidel D, Gray LS, Heron G. Retinotopic accommodation responses in myopia. Invest.Ophthalmol.Vis.Sci. 2003; 44: 1035-1041.

(23) Seidel D, Gray LS, Heron G. The effect of monocular and binocular viewing on the accommodation response to real targets in emmetropia and myopia. Optom.Vis.Sci. 2005; 82 :279285.

(24) Rosenfield M, Wong NN, Solan HA. Nearwork distances in children. Ophthalmic Physiol.Opt. 2001; 21:75-76.

(25) Haro C, Poulain I, Drobe B. Investigation of working distance in myopic and non-myopic children. Optom.Vis.Sci (Suppl) 2000; 77: 189.

(26) Gwiazda JE, Hyman L, Norton TT, Hussein ME, Marsh-Tootle W, Manny R, et al. Accommodation and related risk factors associated with myopia progression and their interaction with treatment in COMET children. Invest.Ophthalmol.Vis.Sci. 2004;45 :2143-2151.

(27) Schaeffel F, Glasser A, Howland HC. Accommodation, refractive error and eye growth in chickens. Vision Res. 1988;28:639-657.

(28) Irving EL, Sivak JG, Callender MG. Refractive plasticity of the developing chick eye. Ophthalmic Physiol.Opt. 1992;12 :448-456.

(29) Wallman J, Winawer J. Homeostasis of eye growth and the question of myopia. Neuron 2004; 43: 447-468. 
(30) Gwiazda J, Hyman L, Hussein M, Everett D, Norton TT, Kurtz D, et al. A randomized clinical trial of progressive addition lenses versus single vision lenses on the progression of myopia in children. Invest.Ophthalmol.Vis.Sci. 2003;44 :1492-1500.

(31) Hasebe S, Ohtsuki H, Nonaka T, Nakatsuka C, Miyata M, Hamasaki I, et al. Effect of progressive addition lenses on myopia progression in Japanese children: a prospective, randomized, double-masked, crossover trial. Invest.Ophthalmol.Vis.Sci. 2008;49: 2781-2789.

(32) Jiang BC, Tea YC, O'Donnell D. Changes in accommodative and vergence responses when viewing through near addition lenses. Optometry 2007; 78 :129-134.

(33) Cheng D, Schmid KL, Woo GC. The effect of positive-lens addition and base-in prism on accommodation accuracy and near horizontal phoria in Chinese myopic children. Ophthalmic Physiol.Opt. 2008 ;28:225-237.

(34) Sreenivasan V, Irving EL, Bobier WR. Binocular Adaptation to +2 D Lenses in Myopic and Emmetropic Children. Optom.Vis.Sci. 2009;86: 731-40.

(35) Berntsen DA, Mutti DO, Zadnik K. The Effect of Bifocal Add on Accommodative Lag in Myopic Children with High Accommodative Lag. Invest.Ophthalmol.Vis.Sci. 2010: 51:6104-10.

(36) Goss DA. Effect of bifocal lenses on the rate of childhood myopia progression.

Am.J.Optom.Physiol.Opt. 1986; 63:135-141.

(37) Goss DA, Grosvenor T. Rates of childhood myopia progression with bifocals as a function of nearpoint phoria: consistency of three studies. Optom.Vis.Sci. 1990;67:637-640.

(38) Fulk GW, Cyert LA, Parker DE. A randomized trial of the effect of single-vision vs. bifocal lenses on myopia progression in children with esophoria. Optom.Vis.Sci. 2000; 77: 395-401.

(39) Goss DA, Rainey BB. Relationship of accommodative response and nearpoint phoria in a sample of myopic children. Optom.Vis.Sci. 1999; 76: 292-294.

(40) Goss DA. Variables related to the rate of childhood myopia progression. Optom.Vis.Sci. 1990;67:631-636.

(41) Chung KM, Chong E. Near esophoria is associated with high myopia. Clin.Exp.Optom. 2000; 83:71-75.

(42) Gwiazda J, Thorn F, Bauer J, Held R. Myopic children show insufficient accommodative response to blur. Invest.Ophthalmol.Vis.Sci. 1993; 34:690-694.

(43) Gwiazda J, Bauer J, Thorn F, Held R. A dynamic relationship between myopia and blur-driven accommodation in school-aged children. Vision Res. 1995; 35:1299-1304. 
(44) Abbott ML, Schmid KL, Strang NC. Differences in the accommodation stimulus response curves of adult myopes and emmetropes. Ophthalmic Physiol.Opt. 1998;18:13-20.

(45) Manny RE, Hussein M, Scheiman M, Kurtz D, Niemann K, Zinzer K, et al. Tropicamide (1\%): an effective cycloplegic agent for myopic children. Invest.Ophthalmol.Vis.Sci. 2001;42:1728-1735.

(46) Rainey BB, Schroeder TL, Goss DA, Grosvenor TP. Inter-examiner repeatability of heterophoria tests. Optom.Vis.Sci. 1998;75:719-726.

(47) Choi M, Weiss S, Schaeffel F, Seidemann A, Howland HC, Wilhelm B, et al. Laboratory, clinical, and kindergarten test of a new eccentric infrared photorefractor (PowerRefractor).

Optom.Vis.Sci. 2000; 77: 537-548.

(48) Seidemann A, Schaeffel F. An evaluation of the lag of accommodation using photorefraction. Vision Res. 2003; 43: 419-430.

(49) Sreenivasan V, Irving EL, Bobier WR. Binocular adaptation to near addition lenses in emmetropic adults. Vision Res. 2008; 48: 1262-1269.

(50) Blade PJ, Candy TR. Validation of the PowerRefractor for measuring human infant refraction. Optom.Vis.Sci. 2006; 83:346-353.

(51) Schaeffel F, Wilhelm H, Zrenner E. Inter-individual variability in the dynamics of natural accommodation in humans: relation to age and refractive errors. J.Physiol. 1993; 461:301-320.

(52) Howland HC. Photorefraction of eyes: history and future prospects. Optom.Vis.Sci. 2009; 86: 603-606.

(53) Wolf KS, Ciuffreda KJ, Jacobs SE. Time course and decay of effects of near work on tonic accommodation and tonic vergence. Ophthalmic Physiol.Opt. 1987;7:131-135.

(54) Millodot M, Lamont A. Letter: Refraction of the periphery of the eye. J.Opt.Soc.Am. 1974; 64:110-111.

(55) Ferree CE, Rand G, Hardy C. Refraction for the peripheral field of vision. Archives of Ophthalmology 1931;5:717-731.

(56) Allen PM, Radhakrishnan H, O'Leary DJ. Repeatability and validity of the PowerRefractor and the Nidek AR600-A in an adult population with healthy eyes. Optom.Vis.Sci. 2003;80:245-251.

(57) Tarrant J, Severson H, Wildsoet CF. Accommodation in emmetropic and myopic young adults wearing bifocal soft contact lenses. Ophthalmic Physiol.Opt. 2008;28:62-72.

(58) Cheng D, Schmid KL, Woo GC, Drobe B. Randomized trial of effect of bifocal and prismatic bifocal spectacles on myopic progression: two-year results. Arch.Ophthalmol. 2010;128:12-19. 
(59) Rosenfield M, Abraham-Cohen JA. Blur sensitivity in myopes. Optom.Vis.Sci. 1999;76:303307.

(60) Schmid KL, Robert Iskander D, Li RW, Edwards MH, Lew JK. Blur detection thresholds in childhood myopia: single and dual target presentation. Vision Res. 2002;42:239-247.

(61) Day M, Seidel D, Gray LS, Strang NC. The effect of modulating ocular depth of focus upon accommodation microfluctuations in myopic and emmetropic subjects. Vision Res. 2008; 49:211-8

(62) Charman WN, Radhakrishnan H. Accommodation, pupil diameter and myopia. Ophthalmic Physiol.Opt. 2009;29:72-79. 
TABLE 1: Critical visual parameters of myopic and emmetropic children

\begin{tabular}{|c|c|c|c|c|c|c|}
\hline \multirow{2}{*}{$\begin{array}{l}\text { PARAMETER } \\
\text { (Mean } \pm \text { SEM; } \\
\text { and range where } \\
\text { applicable) }\end{array}$} & \multicolumn{3}{|c|}{ "EMMETROPES } & \multicolumn{3}{|c|}{ "MYOPES } \\
\hline & Normophores & Exophores & Esophores & Normophores & Exophores & Esophores \\
\hline $\begin{array}{c}\text { No of } \\
\text { participants }\end{array}$ & 11 & 7 & 7 & 10 & 7 & 11 \\
\hline Age (7-14) in yrs & $10.8 \pm 0.43$ & $12.2 \pm 0.63$ & $11.9 \pm 0.43$ & $10.43 \pm 0.53$ & $11.2 \pm 0.8$ & $11.8 \pm 0.63$ \\
\hline $\begin{array}{l}\text { Refractive error } \\
\text { in spherical } \\
\text { equivalent (D) }\end{array}$ & $0.59 \pm 0.09 \mathrm{D}$ & $0.4 \pm 0.09 \mathrm{D}$ & $0.3 \pm 0.09 \mathrm{D}$ & $-2.0 \pm 0.3 \mathrm{D}$ & $-2.5 \pm 0.2 \mathrm{D}$ & $-1.7 \pm 0.3 \mathrm{D}$ \\
\hline Near phoria $(\Delta)$ & $\begin{array}{c}-2.15 \pm 0.49 \\
(0 \text { to } 4 \text { exo } \Delta)\end{array}$ & $\begin{array}{c}-6.72 \pm 0.36 \\
(6 \text { to } 10 \text { exo } \\
\Delta)\end{array}$ & $\begin{array}{l}2.83 \pm 0.58 \\
(2 \text { eso to } 5 \\
\text { eso } \Delta \text { ) }\end{array}$ & $\begin{array}{c}-1.24 \pm 0.94 \\
(0 \text { to } 4 \text { exo } \Delta)\end{array}$ & $\begin{array}{c}-9.7 \pm 1.5 \Delta \\
(6 \text { to } 14 \text { exo } \\
\Delta)\end{array}$ & $\begin{array}{l}4.09 \pm 0.5 \\
(2 \text { eso to } 8 \\
\text { exo } \Delta)\end{array}$ \\
\hline
\end{tabular}




\section{Figure legends}

Figure.1. Example of VAR in the no add, plus add and minus add conditions from a myopic child (left) and an emmetropic child (right). Compared to the no add condition (middle), the plus add (top) reduces the VAR in the myopic child while the VAR of the emmetropic child is unchanged. The minus add (bottom) however, increases the VAR for both the myopic and emmetropic child, but the myopic child shows greater variability than the emmetrope.

Figure.2A and B. Box plot showing VAR in myopic and emmetropic children with different near phoria and add conditions in the binocular (2A) and monocular viewing condition (2B). In both viewing conditions, myopes showed significantly larger variability compared to emmetropes in the no add and minus add condition. The VAR through plus adds were similar in the two refractive groups.

Figure 3: Mean monocular accommodative responses in the myopic and emmetropic groups in the different add conditions. Dashed line represents the accommodative demand through the respective add condition. Myopes show significantly reduced responses compared to emmetropes in the no add and the minus add conditions $(* \mathrm{P}<0.05)$. Error bars indicate $\pm \mathrm{SE}$

Figure 4: Correlation between accommodative error and VAR in the two refractive groups. In both groups, accommodative error significantly correlated with the VAR. Linear regression analysis showed similar slopes but significantly higher VAR (intercept) in myopes compared to emmetropes. 
Myope

Emmetrope

\section{Plus add}
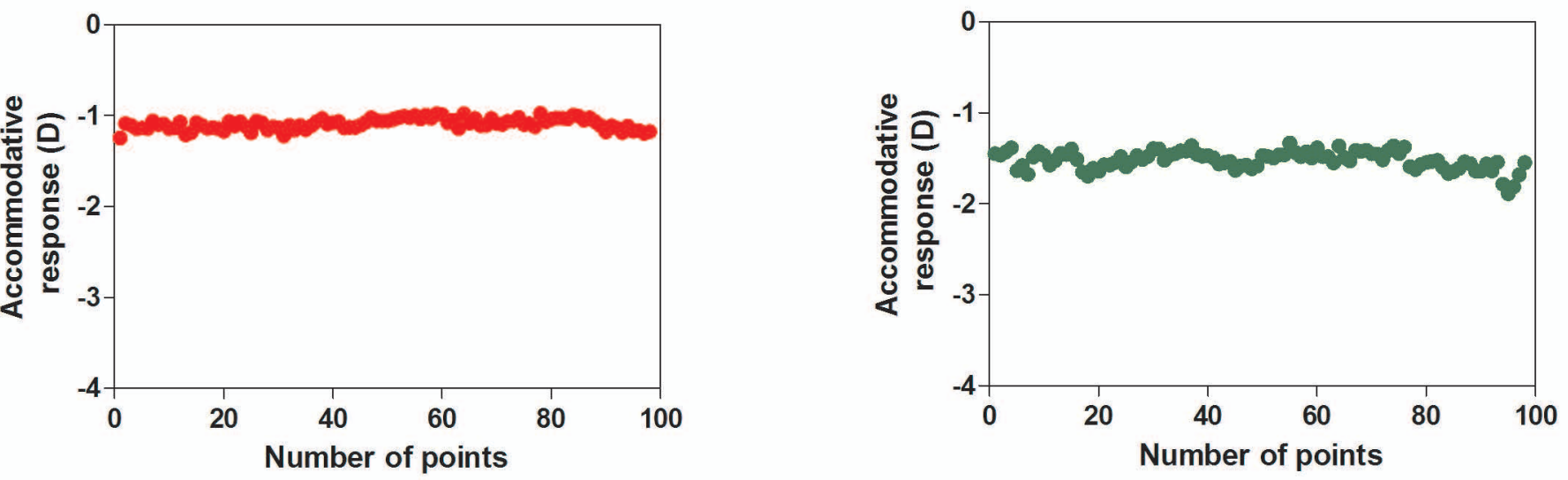

\section{No add}
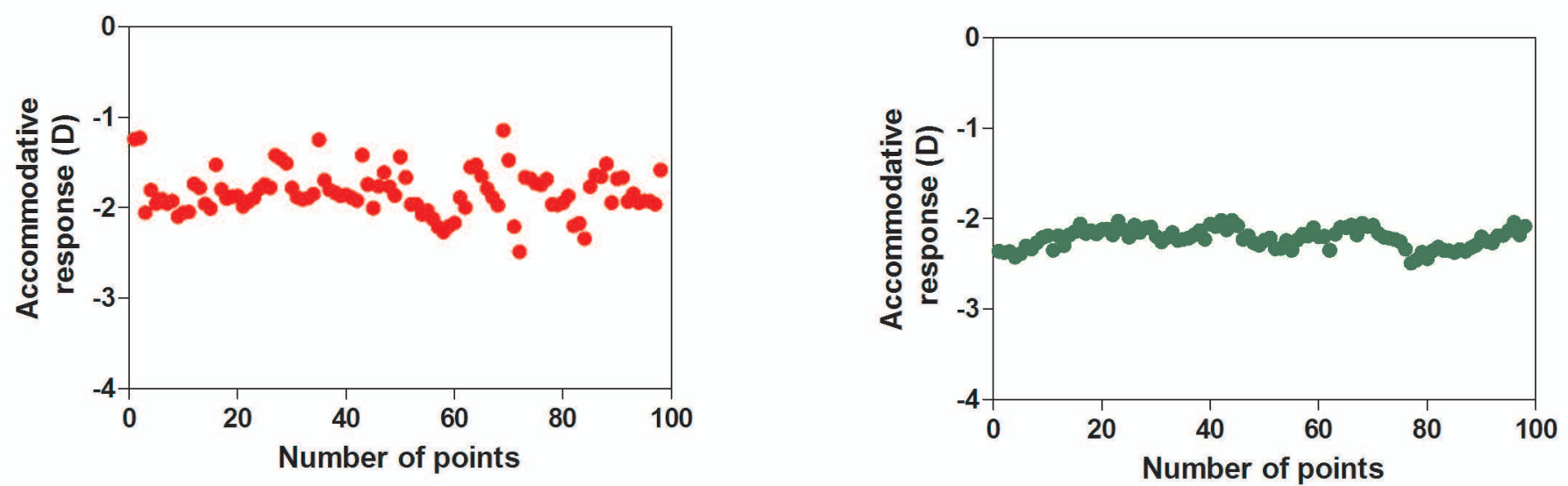

Minus add
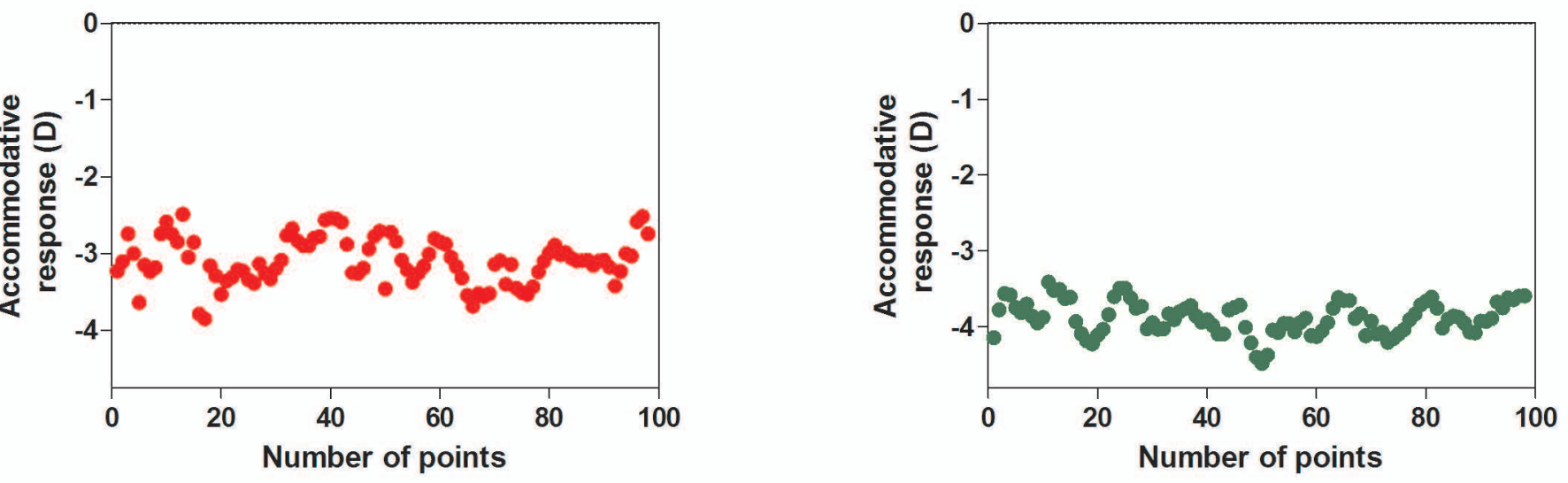


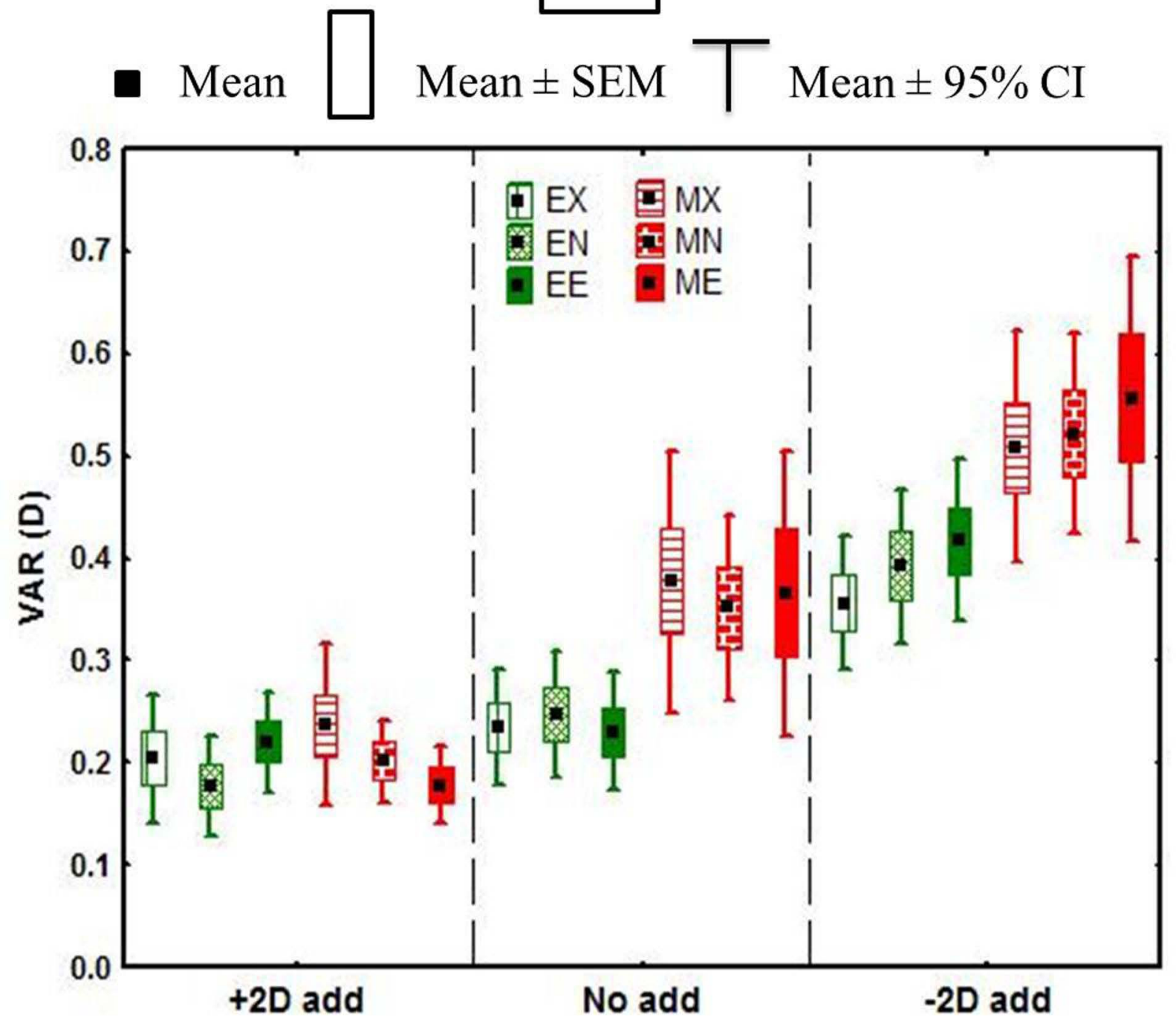




\section{B}

- Mean $\square$ Mean \pm SEM $T_{\text {Mean } \pm 95 \% \text { CI }}$

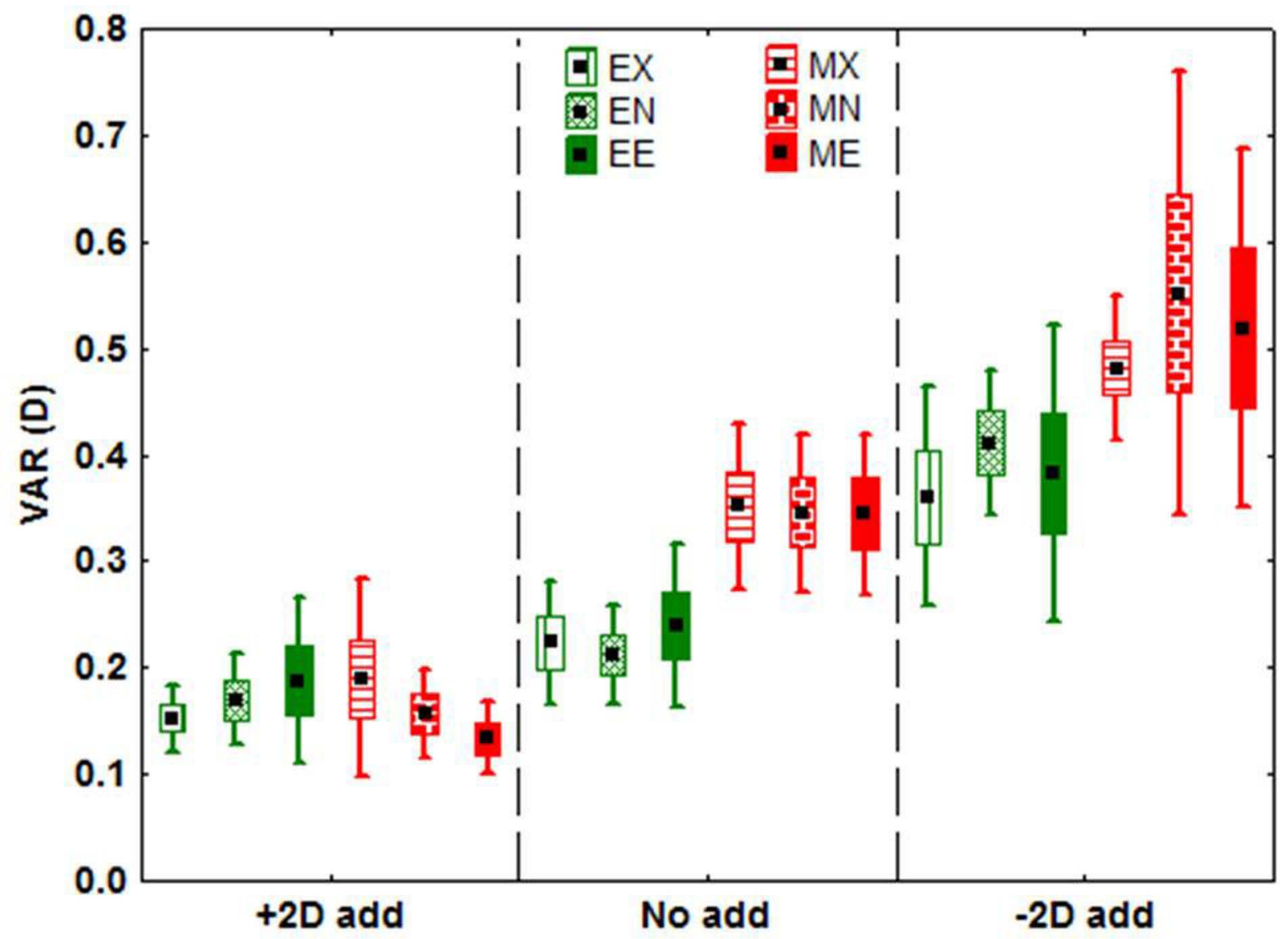




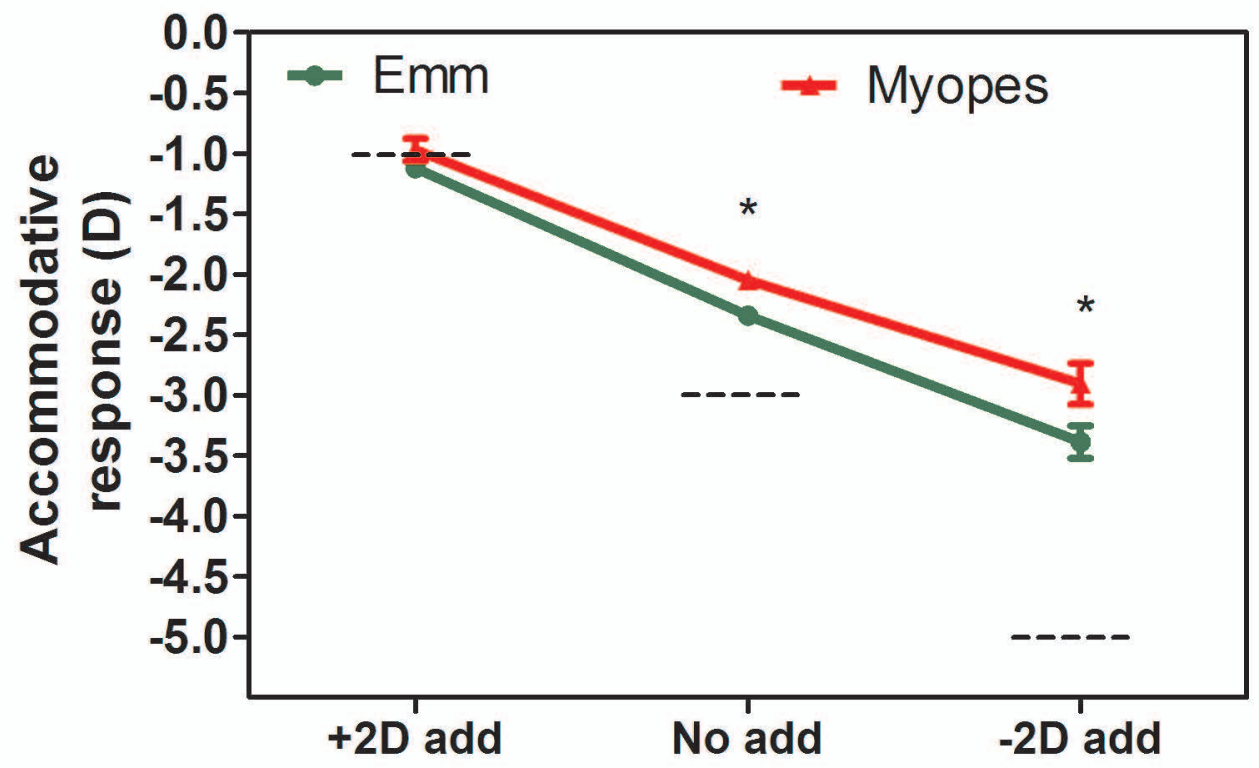




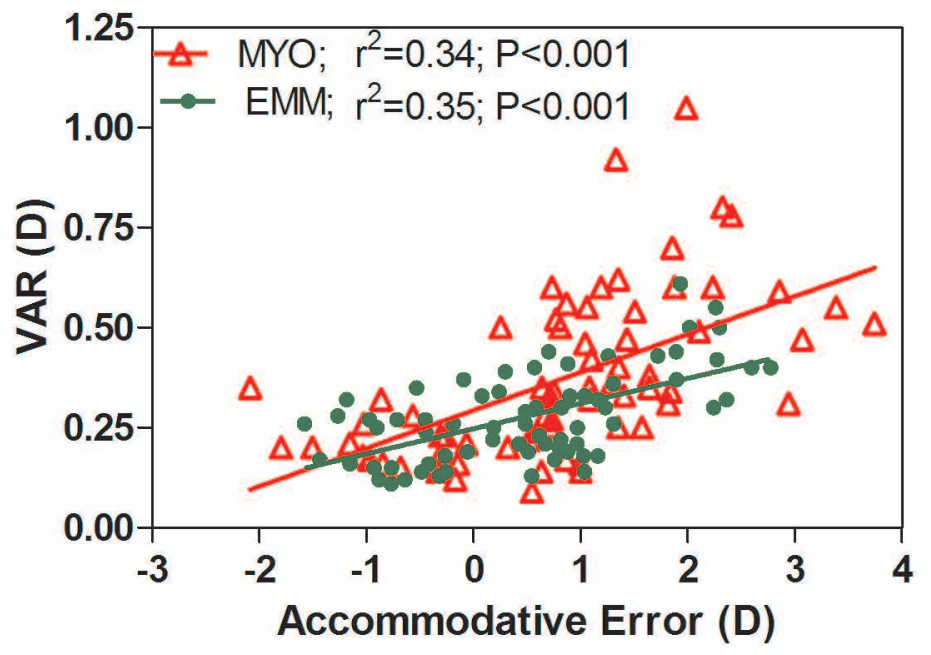

